\title{
Competing Pathways in the 248 nm Photodissociation of Propionyl Chloride and the Barrier to Dissociation of the Propionyl Radical ${ }^{\dagger}$
}

\author{
Laura R. McCunn, Maria J. Krisch, Kana Takematsu, and Laurie J. Butler* \\ The James Franck Institute and Department of Chemistry, The University of Chicago, Chicago, Illinois 60637
}

\begin{abstract}
Jinian Shu
Chemical Sciences Division, Lawrence Berkeley National Laboratory, Berkeley, California 94720
\end{abstract}

Received: January 25, 2004; In Final Form: April 13, 2004

\begin{abstract}
Photofragment translational spectroscopy was used to study the photodissociation of propionyl chloride at $248 \mathrm{~nm}$. The crossed laser-molecular beam experiment with VUV photoionization showed two primary dissociation channels, $\mathrm{C}-\mathrm{Cl}$ bond fission and $\mathrm{HCl}$ elimination. Following cleavage of the $\mathrm{C}-\mathrm{Cl}$ bond, unimolecular dissociation of the propionyl radical produced $\mathrm{CH}_{3} \mathrm{CH}_{2}$ and $\mathrm{CO}$. The energy barrier to the $\mathrm{CH}_{3}-$ $\mathrm{CH}_{2} \mathrm{CO} \rightarrow \mathrm{CH}_{3} \mathrm{CH}_{2}+\mathrm{CO}$ reaction was estimated to be in the range of $16.3 \pm 1.5 \mathrm{kcal} / \mathrm{mol}$ by determining the internal energy distribution of surviving propionyl radicals. No other secondary dissociation channels were observed for the propionyl radical. The $\mathrm{HCl}$ elimination channel, previously reported only for the condensed phase of propionyl chloride, was observed as the minor primary dissociation channel in the gas phase. The cofragment to the $\mathrm{HCl}$ elimination, $\mathrm{CH}_{3} \mathrm{CHCO}$ or $\mathrm{CH}_{2} \mathrm{CH}_{2} \mathrm{CO}$, underwent secondary dissociation to produce $\mathrm{CO}$ and $\mathrm{CH}_{2} \mathrm{CH}_{2}$ with a significant amount of energy partitioned into translational motion.
\end{abstract}

\section{Introduction}

This paper reports the photofragment translational spectroscopy of propionyl chloride, $\mathrm{CH}_{3} \mathrm{CH}_{2} \mathrm{C}(\mathrm{O}) \mathrm{Cl}$, photodissociated at $248.5 \mathrm{~nm}$. The experiments resolve the competing product channels in the primary dissociation of propionyl chloride and determine the energy barrier for secondary dissociation of the propionyl radical. Previous studies of the photolysis of gasphase propionyl chloride ${ }^{1}$ and analogous propionyl compounds ${ }^{2,3}$ have focused on the formation of the propionyl radical. Meanwhile, the existence of an elimination channel, producing $\mathrm{CH}_{3} \mathrm{CHCO}$ or $\mathrm{CH}_{2} \mathrm{CH}_{2} \mathrm{CO}$, has not been adequately investigated. The propionyl radical, which can be generated by photocleavage of the $\mathrm{C}-\mathrm{Cl}$ bond, has received considerable attention because of the significance of acyl radicals to combustion processes and atmospheric chemistry. ${ }^{1,4,5}$ In addition, there is interest in the $\mathrm{CH}_{3} \mathrm{CH}_{2} \mathrm{CO} \rightarrow \mathrm{CH}_{3} \mathrm{CH}_{2}+\mathrm{CO}$ reaction because of its nonstatistical behavior. $2,3,6,7$

There are several energetically allowed reactions for propionyl chloride excited at $248 \mathrm{~nm}$. The most obvious primary channel, $\mathrm{C}-\mathrm{Cl}$ bond fission, and the subsequent secondary reaction producing $\mathrm{CH}_{3} \mathrm{CH}_{2}+\mathrm{CO}$ have been well-documented; ${ }^{1-3,5-11}$ however, there is a scarcity of literature examining any competing dissociation channels, either primary or secondary. The goal of the experiments described below is to determine which primary photodissociation processes occur and what secondary dissociation processes ensue in the resultant radical or molecular primary products. Listed below are the reactions that are energetically possible at $248 \mathrm{~nm}$, with secondary processes indented:

† Part of the special issue "Richard Bersohn Memorial Issue".

* Corresponding author. E-mail: 1jb4@midway.uchicago.edu.

$$
\begin{gathered}
\mathrm{CH}_{3} \mathrm{CH}_{2} \mathrm{COCl} \rightarrow \mathrm{CH}_{3} \mathrm{CH}_{2} \mathrm{CO}+\mathrm{Cl} \\
\Delta H_{0 \mathrm{~K}}=83.1 \mathrm{kcal} / \mathrm{mol}^{12} \\
\mathrm{CH}_{3} \mathrm{CH}_{2} \mathrm{CO} \rightarrow \mathrm{CH}_{3} \mathrm{CH}_{2}+\mathrm{CO} \\
\Delta H_{0 \mathrm{~K}}=9.6 \mathrm{kcal} / \mathrm{mol}^{12} \\
\mathrm{CH}_{3} \mathrm{CH}_{2} \mathrm{COCl} \rightarrow \mathrm{CH}_{3} \mathrm{CH}_{2}+\mathrm{COCl} \\
\Delta H_{0 \mathrm{~K}}=85.7 \mathrm{kcal} / \mathrm{mol}^{12} \\
\mathrm{CH}_{3} \mathrm{CH}_{2} \mathrm{COCl} \rightarrow \mathrm{CH}_{3} \mathrm{CHCO}+\mathrm{HCl} \\
\Delta H_{0 \mathrm{~K}}=17.5 \mathrm{kcal} / \mathrm{mol}^{12} \\
\mathrm{CH}_{3} \mathrm{CHCO}^{\rightarrow} \mathrm{CH}_{2} \mathrm{CH}_{2}+\mathrm{CO} \\
\Delta H_{0 \mathrm{~K}}=7.7 \mathrm{kcal} / \mathrm{mol}^{12} \\
\mathrm{CH}_{3} \mathrm{CH}_{2} \mathrm{COCl} \rightarrow \mathrm{CH}_{2} \mathrm{CH}_{2} \mathrm{CO}+\mathrm{HCl} \\
\Delta H_{0 \mathrm{~K}}=43.1 \mathrm{kcal} / \mathrm{mol}^{12,13} \\
\mathrm{CH}_{2} \mathrm{CH}_{2} \mathrm{CO} \rightarrow \mathrm{CH}_{2} \mathrm{CH}_{2}+\mathrm{CO} \\
\Delta H_{0 \mathrm{~K}}=-17.9 \mathrm{kcal} / \mathrm{mol}^{13}
\end{gathered}
$$

Studies by our group on acetyl chloride and bromoacetyl chloride explain the mechanism for $\alpha$-bond cleavage of acyl chlorides..$^{14}$ Absorption of a $248 \mathrm{~nm}$ photon excites a ${ }^{1}\left(\pi^{*} \leftarrow n\right)$

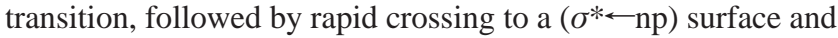
breaking of the $\mathrm{C}-\mathrm{Cl}$ bond. ${ }^{12}$ Whereas all previously published experiments on this molecule in the gas phase have examined only the $\mathrm{C}-\mathrm{Cl}$ bond fission channel, Winter et al. identified an $\mathrm{HCl}$ elimination channel for propionyl chloride isolated in an argon matrix at $10 \mathrm{~K} .{ }^{12}$ Using a polarized laser for photodissociation, they were able to show that elimination must occur by a direct mechanism, instead of $\mathrm{H}$ abstraction by the $\mathrm{Cl}$ atom. 
Studies with deuterium-labeled propionyl chloride established that the reaction proceeds strictly by $\alpha$-elimination (fourcentered).

Although there are a few published experiments regarding the kinetics and energy barrier of the radical dissociation $\mathrm{CH}_{3-}$ $\mathrm{CH}_{2} \mathrm{CO} \rightarrow \mathrm{CH}_{3} \mathrm{CH}_{2}+\mathrm{CO}$, they date back approximately 30 years. In the earliest study, Kerr and Lloyd produced the propionyl radical by means of photolysis of azoethane in the presence of propionaldehyde. From their measurements of rate constants, they concluded that the barrier to propionyl decomposition is $14.6 \mathrm{kcal} / \mathrm{mol} .{ }^{9,10}$ Watkins and Thompson performed similar experiments with azoethane and $\mathrm{CO}$ and found a barrier of $14.7 \mathrm{kcal} / \mathrm{mol}^{8}{ }^{8}$ More recently, two experimental studies ${ }^{2,3}$ evaluated nonstatistical behavior in the dynamics of the propionyl radical dissociation and involved calculations that used a different value, $17 \mathrm{kcal} / \mathrm{mol}$, for the dissociation barrier. This number was used based on a dissociation energy of $13 \mathrm{kcal} /$ $\mathrm{mol}$ and the $4.8 \mathrm{kcal} / \mathrm{mol}$ activation energy ${ }^{8}$ for the reverse addition reaction and is similar to the experimentally determined value for the $\mathrm{CH}_{3} \mathrm{CO} \rightarrow \mathrm{CH}_{3}+\mathrm{CO}$ barrier. ${ }^{15}$

In response to the interest in the dynamics of propionyl radical decomposition, there have been theoretical predictions of the energy barrier to dissociation. These calculations agree most closely with the early experimental values of Kerr and Lloyd and of Watkins and Thompson. Calculations by Martinez-Nunez and Vazquez-Rodriguez predict a zero-point-corrected barrier of $14.9 \mathrm{kcal} / \mathrm{mol}$ at CBS-QB3 level. ${ }^{6}$ Méreau et al. calculated a $15.6 \mathrm{kcal} / \mathrm{mol}$ barrier at $298 \mathrm{~K}$ by an ab initio G2(MP2) method and $15.8 \mathrm{kcal} / \mathrm{mol}$ by a DFT (B3LYP) method. ${ }^{5}$

Our experiments provide a method to determine this barrier directly by photodissociating propionyl chloride at $248.5 \mathrm{~nm}$. Given the photon energy of $114.9 \mathrm{kcal} / \mathrm{mol}$ and a $\mathrm{C}-\mathrm{Cl}$ bond energy of approximately $83.1 \mathrm{kcal} / \mathrm{mol},{ }^{12}$ a portion of the nascent propionyl radicals may not have sufficient internal energy to overcome the dissociation barrier. In this paper, we report the detection of both stable propionyl radicals and the secondary dissociation products $\mathrm{CH}_{3} \mathrm{CH}_{2}+\mathrm{CO}$ of the unstable radicals and make a rough determination of the barrier to dissociation.

\section{Experimental Method}

Photofragment translational spectroscopy was performed on the rotating-source crossed laser-molecular beam apparatus on the Chemical Dynamics Beamline at Lawrence Berkeley National Laboratory's Advanced Light Source (ALS). Details of the experimental apparatus have been described previously. ${ }^{16}$ A $6.6 \%$ propionyl chloride-He molecular beam was created by bubbling $\mathrm{He}$ (605 Torr total backing pressure) through propionyl chloride cooled to $12{ }^{\circ} \mathrm{C}$ and expanding it through a piezoelectric pulsed valve $(0.5 \mathrm{~mm}$ orifice $)$ operating at 100 $\mathrm{Hz}$. The nozzle was heated to $153{ }^{\circ} \mathrm{C}$ to reduce cluster formation. The molecular beam of the parent molecule was characterized by directing the beam through a chopper wheel straight into the detector. The measured number-density velocity of the propionyl chloride molecular beam for the data presented here typically peaked at $1.3 \times 10^{5} \mathrm{~cm} / \mathrm{s}$ with a fwhm of $20 \%$.

Photodissociation was accomplished with a Lambda Physik COMPex 110 excimer laser operating at the $248.5 \mathrm{~nm} \mathrm{KrF}$ transition with a pulse energy of $200 \mathrm{~mJ} /$ pulse. The laser beam was focused to an area of $1.8 \mathrm{~mm} \times 5.0 \mathrm{~mm}$, intersecting the molecular beam at a $90^{\circ}$ angle in the interaction region. Photofragments recoiling in the direction of the detector traveled $15.1 \mathrm{~cm}$ to the ionizing region, where tunable VUV synchrotron radiation ionized a portion of the fragments. Photoionization energies were selected by tuning the gap of a U10 undulator,

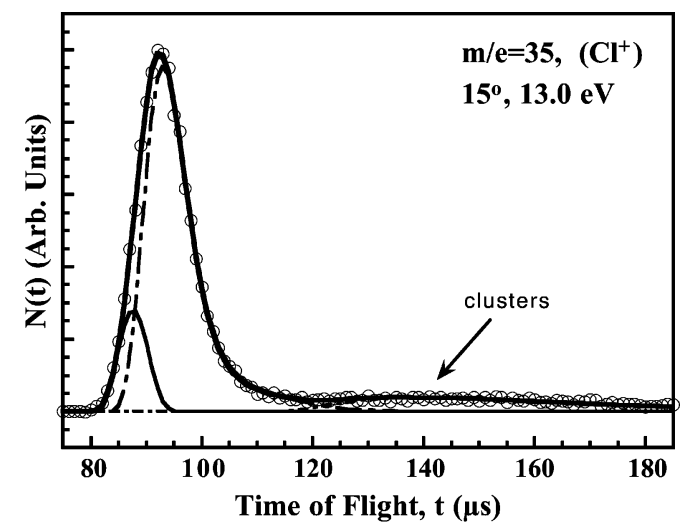

Figure 1. TOF spectrum for $m / e=35\left(\mathrm{Cl}^{+}\right)$from the photodissociation of propionyl chloride at $248 \mathrm{~nm}$. Open circles represent experimental data taken at $13.0 \mathrm{eV}$ photoionization energy and a source angle of $15^{\circ}$ for 20000 laser shots. The thin solid line fits high recoil kinetic energy chlorine atoms with momentum-matched propionyl radicals that are stable to secondary dissociation. The low recoil kinetic energy chlorine atoms are fit by the long-dash-dotted line. The short-dashdotted line shows signal from clusters. The thick solid line is the overall forward convolution fit using the $P\left(E_{\mathrm{T}}\right)$ in Figure 2 .

which generated the radiation. The necessary undulator gap (mm) was calculated from the desired photoionization energy, $x(\mathrm{eV})$, using the following polynomial: ${ }^{17}$

$$
\begin{aligned}
& \operatorname{gap}(\mathrm{mm})=7.875(\mathrm{~mm})+2.5054(\mathrm{~mm} / \mathrm{eV}) x- \\
& 0.068545\left(\mathrm{~mm} / \mathrm{eV}^{2}\right) x^{2}+0.00082477\left(\mathrm{~mm} / \mathrm{eV}^{3}\right) x^{3}
\end{aligned}
$$

For example, $\mathrm{CH}_{3} \mathrm{CH}_{2}$ data at $m / e=29$ were collected using an $11.0 \mathrm{eV}$ photoionization energy, requiring a $28.238 \mathrm{~mm}$ undulator gap. Unwanted higher harmonics of VUV radiation were removed by an argon gas filter. The VUV beam was defined by a $10 \mathrm{~mm} \times 10 \mathrm{~mm}$ aperture.

Ionized photofragments were mass-selected by an Extrel 2.1 $\mathrm{MHz}$ quadrupole mass spectrometer and then counted by a Daly detector. The total time-of-flight (TOF) from the interaction region to the detector was recorded for the photofragments. An ion flight constant of $5.72 \mu \mathrm{s} \cdot \mathrm{amu}^{-1 / 2}$ was used to account for the time spent as ions in the detector. Recoil translational energy distributions were found by forward convolution fitting of the TOF spectra.

\section{Results and Analysis}

The data evidenced that both $\mathrm{C}-\mathrm{Cl}$ bond fission and $\mathrm{HCl}$ elimination occur in the photodissociation of propionyl chloride at $248 \mathrm{~nm}$. $\mathrm{C}-\mathrm{Cl}$ fission was evidenced by the $\mathrm{Cl}^{+}$signal at $m / e=35$ shown in Figure 1 .

The total recoil kinetic energy bimodal distribution $P\left(E_{\mathrm{T}}\right)$ in $\mathrm{C}-\mathrm{Cl}$ fission was determined by forward convolution fitting of the data and is shown in Figure 2. The high recoil kinetic energy $\mathrm{Cl}$ atoms momentum-match to low internal energy propionyl radicals that do not undergo secondary dissociation. The $\mathrm{Cl}$ atoms with low recoil kinetic energy correspond to the momentum-matched propionyl radicals with high internal energy that is sufficient for secondary dissociation. The $E_{\mathrm{T}}$ marking the onset of dissociation of the unstable propionyl radicals gave us an estimate of the energy barrier to dissociation, as described in the Discussion. A signal from cluster fragments also appeared in the $m / e=35 \mathrm{TOF}$. Despite increasing the nozzle temperature by $40^{\circ} \mathrm{C}$ to $153^{\circ} \mathrm{C}$, the cluster signal could not be completely eradicated.

A TOF spectrum taken at $m / e=36\left(\mathrm{H}^{35} \mathrm{Cl}^{+}\right)$and a $30^{\circ}$ source angle (Figure 3 ) indicated the presence of an $\mathrm{HCl}$ elimination 


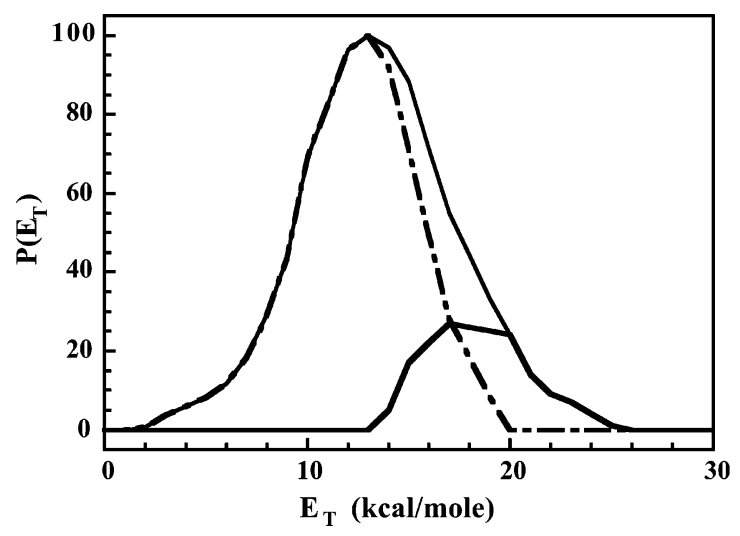

Figure 2. Unnormalized $P\left(E_{\mathrm{T}}\right)$ for $\mathrm{C}-\mathrm{Cl}$ bond fission at $248 \mathrm{~nm}$ derived from the forward convolution fitting of the $m / e=35 \mathrm{TOF}$ spectrum shown in Figure 1. The bold solid line shows the high recoil kinetic energy $\mathrm{C}-\mathrm{Cl}$ bond fission and the dash-dotted line corresponds to low recoil kinetic energy. The total $P\left(E_{\mathrm{T}}\right)$ is shown by the solid line.

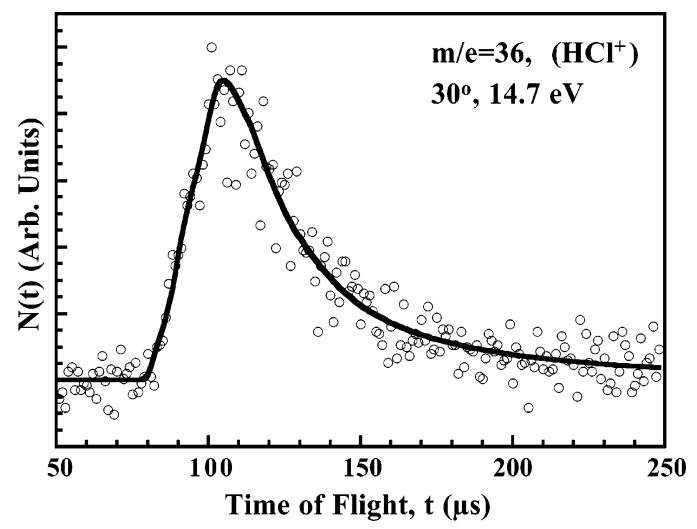

Figure 3. TOF spectrum of $m / e=36\left(\mathrm{HCl}^{+}\right)$taken at $14.7 \mathrm{eV}$ photoionization energy and a source angle of $30^{\circ}$ for 30000 laser shots. Open circles represent experimental data and the solid line is the forward convolution fit using the $P\left(E_{\mathrm{T}}\right)$ in Figure 4.

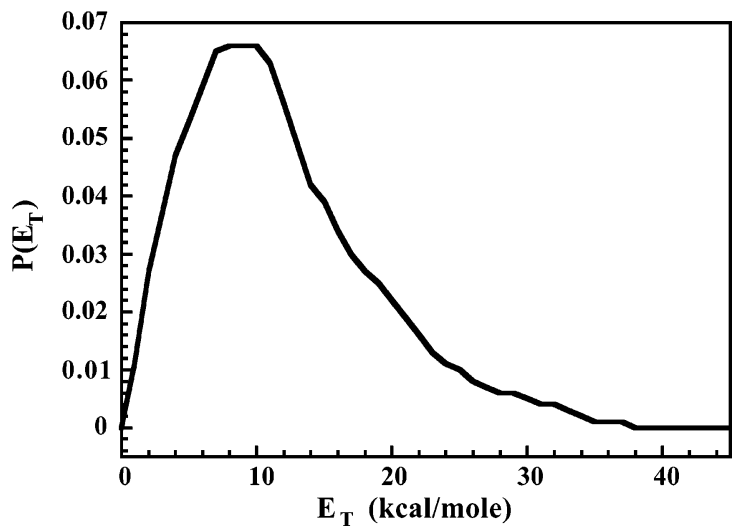

Figure 4. Normalized $P\left(E_{\mathrm{T}}\right)$ for $\mathrm{HCl}$ elimination derived from the forward convolution fitting of the $m / e=36\left(\mathrm{HCl}^{+}\right)$TOF spectrum shown in Figure 3.

channel. The data were fit by a single $P\left(E_{\mathrm{T}}\right)$, shown in Figure 4, which was slower and broader than the $\mathrm{C}-\mathrm{Cl}$ bond fission $P\left(E_{\mathrm{T}}\right)$ (Figure 2). To determine a rough branching ratio between $\mathrm{Cl}^{+}$and $\mathrm{HCl}^{+}$, we integrated the signal in the respective background-subtracted TOF spectra. A $m / e=35\left(\mathrm{Cl}^{+}\right)$TOF spectrum taken at a $30^{\circ}$ source angle with an ionization energy of $15.0 \mathrm{eV}$ and $14.2 \mathrm{~mW}$ power was integrated in the range of $75-130 \mu \mathrm{s}$, excluding signal from clusters. This is not the TOF spectrum shown in Figure 1, as we chose $\mathrm{Cl}^{+}$and $\mathrm{HCl}^{+}$spectra

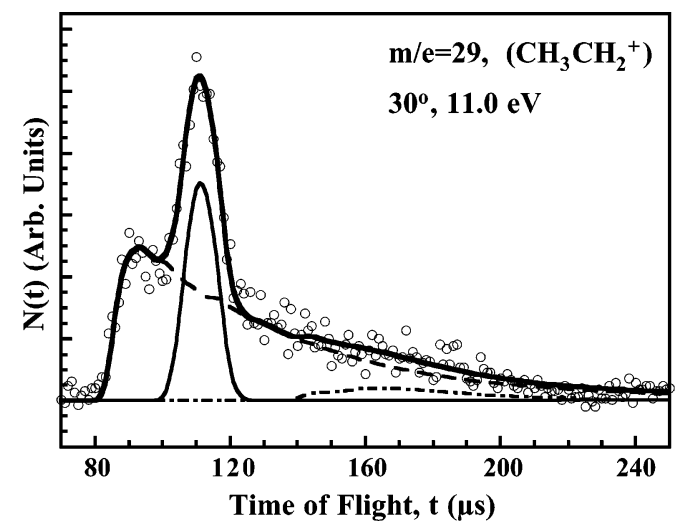

Figure 5. TOF spectrum for $m / e=29\left(\mathrm{CH}_{3} \mathrm{CH}_{2}{ }^{+}\right)$at $248 \mathrm{~nm}$. Open circles represent experimental data taken at $11.0 \mathrm{eV}$ photoionization energy and a source angle of $30^{\circ}$ for 100000 laser shots. The bold solid line is the overall forward convolution fit using the $P\left(E_{\mathrm{T}}\right)$ in Figure 6. Ethyl radicals produced from secondary dissociation of slow propionyl radicals are shown by the dashed line. The thin solid line shows fast, stable propionyl radicals that fragment to $m / e=29$ in the ionizer. The dash-dotted line shows signal contribution from clusters.

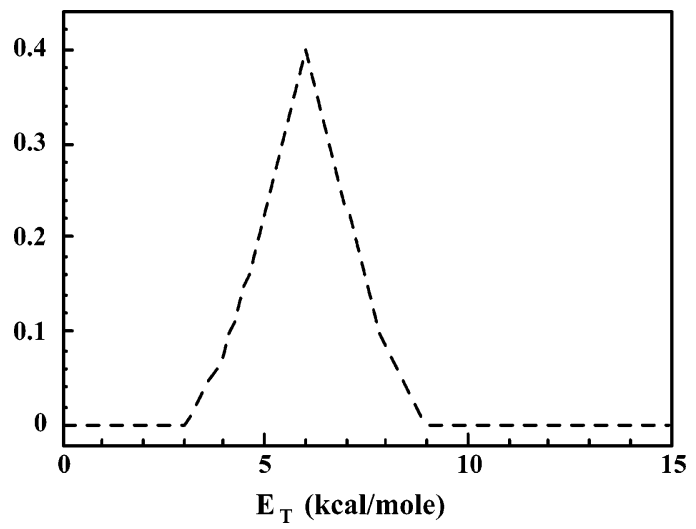

Figure 6. Normalized $P\left(E_{\mathrm{T}}\right)$ for dissociation of the propionyl radical derived from the forward convolution fitting of the $m / e=29\left(\mathrm{CH}_{3}\right.$ $\mathrm{CH}_{2}{ }^{+}$) TOF spectrum shown in Figure 5.

that were collected on the same day, with identical beam conditions and the same source angle. The $m / e=36\left(\mathrm{HCl}^{+}\right)$ TOF spectrum at a $30^{\circ}$ source angle with $14.7 \mathrm{eV}$ ionization energy $(10.6 \mathrm{~mW})$ was integrated from 60 to $200 \mu \mathrm{s}$. Accounting for the appropriate Jacobian factors and normalizing for ALS photoflux gave a $[\mathrm{Cl}] /[\mathrm{HCl}]$ branching ratio of 6.5 , given that the photoionization cross sections of $\mathrm{Cl}$ and $\mathrm{HCl}$ are nearly equal. ${ }^{18,19}$ The determination is qualitative, as it could not account for the fact that other data we have taken show that the $\mathrm{HCl}^{+}$signal is not linear in ALS power. ${ }^{20} \mathrm{We}$ looked for evidence of $\mathrm{C}-\mathrm{C}$ bond fission by examining the TOF spectrum for $m / e=63\left(\mathrm{COCl}^{+}\right)$at a $15^{\circ}$ source angle and $15.0 \mathrm{eV}$ ionization energy. No signal above the noise was observed after 50000 laser shots. Also, all components of the signal at $m / e=$ $29\left(\mathrm{CH}_{3} \mathrm{CH}_{2}{ }^{+}\right)$were adequately fit by processes other than primary $\mathrm{C}-\mathrm{C}$ fission, as described below.

Following cleavage of the $\mathrm{C}-\mathrm{Cl}$ bond, unimolecular dissociation of the nascent propionyl radicals with high internal energies produced $\mathrm{CH}_{3} \mathrm{CH}_{2}$ and $\mathrm{CO}$. Figure 5 shows the TOF for $m / e=29\left(\mathrm{CH}_{3} \mathrm{CH}_{2}{ }^{+}\right)$at a $30^{\circ}$ source angle. The low, fast peak of the TOF, fit by the dashed line, is the $\mathrm{CH}_{3} \mathrm{CH}_{2}$ signal from the dissociation of the propionyl radicals. The $P\left(E_{\mathrm{T}}\right)$ for the $\mathrm{CH}_{3} \mathrm{CH}_{2} \mathrm{CO} \rightarrow \mathrm{CH}_{3} \mathrm{CH}_{2}+\mathrm{CO}$ products was then determined to be sharply peaked at $6 \mathrm{kcal} / \mathrm{mol}$ (Figure 6). It was determined by forward convolution fitting of the TOF, accounting for both the velocity imparted to the dissociating propionyl 


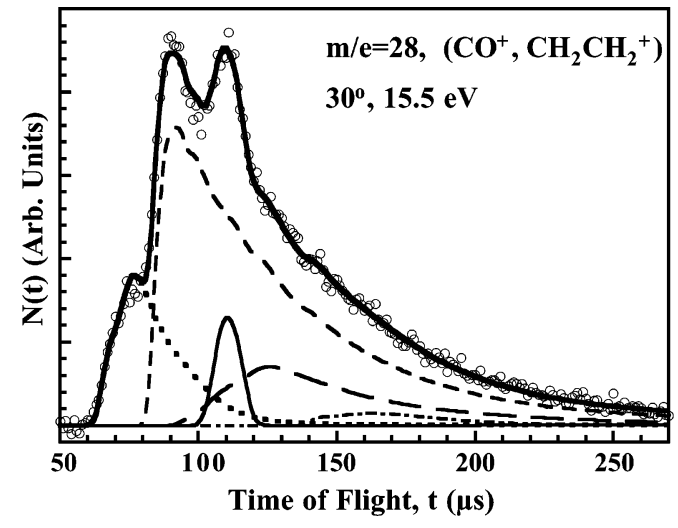

Figure 7. TOF spectrum for $m / e=28\left(\mathrm{CO}^{+}, \mathrm{CH}_{2} \mathrm{CH}_{2}{ }^{+}\right)$at $248 \mathrm{~nm}$. Open circles represent experimental data taken at $15.5 \mathrm{eV}$ photoionization energy and a source angle of $30^{\circ}$ for 100000 laser shots. The bold solid line is the overall forward convolution fit using the $P\left(E_{\mathrm{T}}\right)$ in Figure 8. The dotted line is $\mathrm{CO}$ and $\mathrm{CH}_{2} \mathrm{CH}_{2}$ from dissociation of the $\mathrm{C}_{3} \mathrm{H}_{4} \mathrm{O}$ fragment resulting from $\mathrm{HCl}$ elimination. Stable $\mathrm{C}_{3} \mathrm{H}_{4} \mathrm{O}$ photofragments that crack in the ionizer to $m / e=28$ appear at the long dashed line in the spectrum. CO produced from dissociation of slow propionyl radicals is shown by the medium dashed line. The thin solid line shows fast, stable propionyl radicals that fragment to $m / e=28$ in the ionizer. The dash-dotted line shows signal contribution from clusters.

radicals using the dot - dashed portion of the $\mathrm{C}-\mathrm{Cl}$ bond fission $P\left(E_{\mathrm{T}}\right)$ in Figure 2 and the recoil of the $\mathrm{CH}_{3} \mathrm{CH}_{2}$ from the $\mathrm{CO}$ in the dissociation of these radicals.

The solid line component of the TOF in Figure 5 shows the signal that was fit by using the high $E_{\mathrm{T}}$ portion of the $P\left(E_{\mathrm{T}}\right)$ for $\mathrm{C}-\mathrm{Cl}$ fission in Figure 2. Using the full $P\left(E_{\mathrm{T}}\right)$ gave an unsatisfactory fit, so it was necessary to use only the high $E_{\mathrm{T}}$ distribution from Figure 2. Although we could not find the appearance energy of $\mathrm{CH}_{3} \mathrm{CH}_{2}{ }^{+}$in the literature, this component is believed to come from stable propionyl radicals that fragment to $m / e=29$ upon photoionization. There is also an appreciable contribution from clusters to TOF signal, shown by the dashdotted line in Figure 5.

Figure 7 shows the $m / e=28\left(\mathrm{CO}^{+}, \mathrm{CH}_{2} \mathrm{CH}_{2}{ }^{+}\right)$TOF spectrum containing components derived from both the $\mathrm{C}-\mathrm{Cl}$ fission and $\mathrm{HCl}$ elimination pathways. Most of the signal in the complicated spectrum is fit easily by kinetic energy distributions determined by the detection of other masses. The dashed line shows the signal from $\mathrm{CO}$ produced in the secondary dissociation of the propionyl radical (reaction 2). The $P\left(E_{\mathrm{T}}\right)$, shown in Figure 6, used to fit this portion of the $m / e=28$ signal was determined from fitting the cleaner signal from the partner fragment $\mathrm{CH}_{3}$ $\mathrm{CH}_{2}$. Again, propionyl radicals that are stable to secondary dissociation appear in the spectrum due to cracking in the ionizer. The fit and $P\left(E_{\mathrm{T}}\right)$ for these radicals are shown by the solid line in Figures 7 and 2, respectively. The dash-dotted line shows a small signal contribution from clusters.

The only remaining undetermined signal in the spectrum is due to the $\mathrm{C}_{3} \mathrm{H}_{4} \mathrm{O}$ cofragment to the $\mathrm{HCl}$ elimination (reaction 4 or 6). By assuming that some of the $\mathrm{C}_{3} \mathrm{H}_{4} \mathrm{O}$ produced underwent secondary dissociation to produce $\mathrm{CO}$ and $\mathrm{CH}_{2} \mathrm{CH}_{2}$ (reaction 5 or 7) and some, formed in coincidence with higher translational energy $\mathrm{HCl}$ product, was stable to secondary dissociation, we were able to fit the remaining signal. The latter contribution was calculated from the $P\left(E_{\mathrm{T}}\right)$ for $\mathrm{HCl}$ elimination shown in Figure 4 with the resulting fit shown by the longdashed line in Figure 7. Although $\mathrm{C}_{3} \mathrm{H}_{4} \mathrm{O}$ formed in coincidence with high translational energy $\mathrm{HCl}$ should be most stable, we

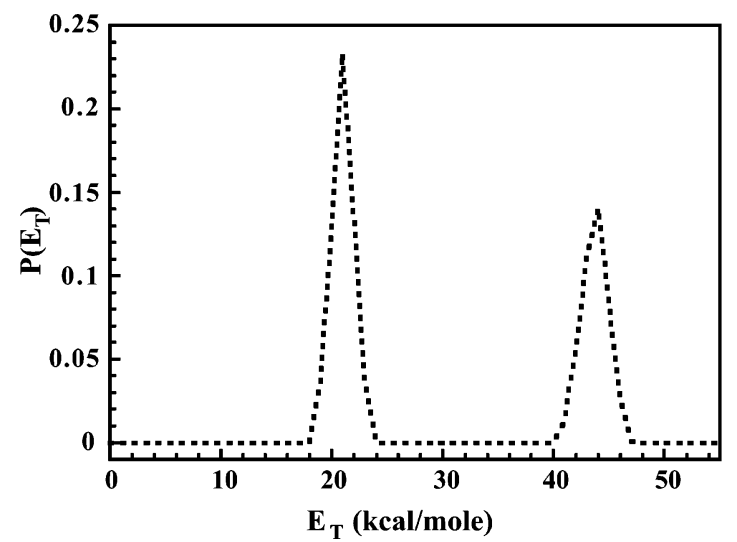

Figure 8. Normalized $P\left(E_{\mathrm{T}}\right)$ for dissociation of the $\mathrm{C}_{3} \mathrm{H}_{4} \mathrm{O}$ photofragments of $\mathrm{HCl}$ elimination. It was determined from forward convolution fitting of the TOF spectrum in Figure 7 that a bimodal distribution best fit the data.

fit the data presuming that the fraction of stable $\mathrm{C}_{3} \mathrm{H}_{4} \mathrm{O}$ product is constant across the primary recoil kinetic energy distribution. The remaining $\mathrm{CO}$ and $\mathrm{CH}_{2} \mathrm{CH}_{2}$ signal from the secondary dissociation of the unstable $\mathrm{C}_{3} \mathrm{H}_{4} \mathrm{O}$ produced from $\mathrm{HCl}$ elimination was fit by forward convolution, giving the dotted line contribution in Figure 7. The fit accounted for the primary recoil between the $\mathrm{HCl}$ and $\mathrm{C}_{3} \mathrm{H}_{4} \mathrm{O}$ product using the $P\left(E_{\mathrm{T}}\right)$ in Figure 4 and the recoil for the $\mathrm{C}_{3} \mathrm{H}_{4} \mathrm{O} \rightarrow \mathrm{CH}_{2} \mathrm{CH}_{2}+\mathrm{CO}$ secondary process determined by forward convolution fitting of the fast signal. The $P\left(E_{\mathrm{T}}\right)$ for this process is peculiar because the fast edge of the TOF could only be fit by assuming a bimodal $P\left(E_{\mathrm{T}}\right)$ for the secondary dissociation, as shown by the dotted line in Figure 8 . Though there was considerable latitude in the forms of the $P\left(E_{\mathrm{T}}\right)$ that gave an acceptable fit of the signal, they all had a bimodal nature. This indicates that there may be two different mechanisms occurring in the secondary dissociation of the $\mathrm{C}_{3} \mathrm{H}_{4} \mathrm{O}$ fragment. The higher kinetic energy portion of the $P\left(E_{\mathrm{T}}\right)$ may also be due to a multiphoton process, although we did not perform a laser power dependence study to confirm this. A substantial amount of the available energy is partitioned into the translational motion of the $\mathrm{C}_{2} \mathrm{H}_{4}$ and $\mathrm{CO}$ fragments. This is in accordance with the large exit barrier of $74.6 \mathrm{kcal} /$ mol for the $\mathrm{CH}_{3} \mathrm{CHCO} \rightarrow \mathrm{CH}_{2} \mathrm{CH}_{2}+\mathrm{CO}$ reaction predicted by Schalley et al. ${ }^{13}$

\section{Discussion}

The data presented here allow for a determination of the barrier to propionyl dissociation as the $\mathrm{Cl}$ atom TOF determines the internal energy of all nascent propionyl radicals and the signal fit in Figure 5 indicates which of the radicals survive secondary dissociation. Then the internal energy of propionyl radical that marks the onset of secondary dissociation is found by comparing the two fits. The internal energy, $E_{\text {int }}$, of the propionyl radical is obtained by the following energy conservation relationship:

$$
E_{\text {parent }}+E_{h v}=D_{0}(\mathrm{C}-\mathrm{Cl})+E_{\text {int }}+E_{\mathrm{Cl}}+E_{\mathrm{T}}
$$

$E_{h v}$, the energy of a $248.5 \mathrm{~nm}$ photon, is equal to $114.9 \mathrm{kcal} /$ mol, accounting for the air-to-vacuum correction. $D_{0}(\mathrm{C}-\mathrm{Cl})$ is taken as $83.1 \mathrm{kcal} / \mathrm{mol} .{ }^{12} E_{\text {parent }}$ is the energy of the propionyl chloride molecule; we estimate it by assuming that vibrational energy is not cooled by the nozzle expansion. Using previously published vibrational modes, ${ }^{12}$ the average vibrational energy of a propionyl chloride molecule was calculated to be $4.0 \mathrm{kcal} /$ $\mathrm{mol}$ at the nozzle temperature of $153^{\circ} \mathrm{C} . E_{\mathrm{Cl}}$ refers to the energy 


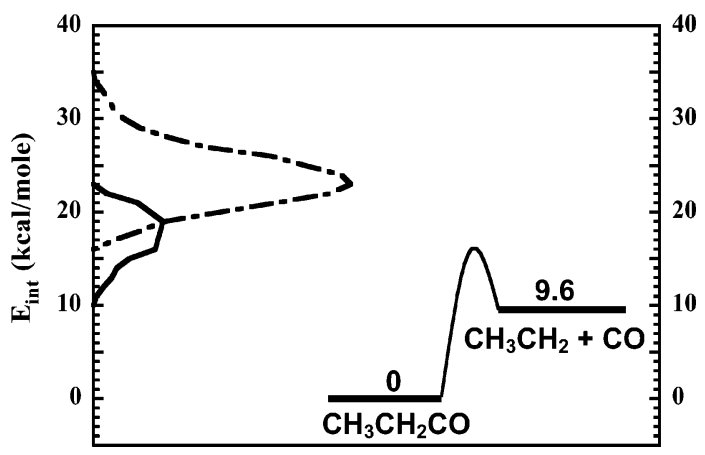

Figure 9. Internal energy $\left(E_{\text {int }}\right)$ of the propionyl radical compared to the enthalpies of the propionyl radical and its secondary dissociation products $\mathrm{CH}_{3} \mathrm{CH}_{2}$ and $\mathrm{CO}$. Enthalpies are taken from ref 12. $E_{\text {int }}$ was calculated from $E_{h v}+E_{\text {parent }}=D_{0}(\mathrm{C}-\mathrm{Cl})+E_{\text {int }}+E_{\mathrm{Cl}}+E_{\mathrm{T}}$, where $E_{\mathrm{T}}$ was taken from the $P\left(E_{\mathrm{T}}\right)$ of the $\mathrm{C}-\mathrm{Cl}$ bond fission channel. (Figure 2) The $E_{\text {int }}$ shown in the figure is calculated assuming $\mathrm{Cl}\left({ }^{2} \mathrm{P}_{3 / 2}\right)$, so $E_{\mathrm{Cl}}$ $=0 \mathrm{kcal} / \mathrm{mol}$, but both spin-orbit states of $\mathrm{Cl}$ are likely produced, so we address this in the discussion. Also, $E_{\text {int }}$ was calculated using $E_{\text {parent }}$ $=4 \mathrm{kcal} / \mathrm{mol}$, which does not account for the possible spread in vibrational energies of the parent molecule. The solid line corresponds to propionyl radicals that do not dissociate. These propionyl radicals correspond to $\mathrm{Cl}$ atoms detected at $m / e=35$ (Figure 1) with high recoil kinetic energy. (Figure 2) The dash-dotted line refers to propionyl radicals with sufficient energy to overcome the secondary dissociation barrier, producing $\mathrm{CH}_{3} \mathrm{CH}_{2}$ that was detected at $m / e=29$ (Figure 5) and $\mathrm{CO}$ detected at $m / e=28$. (Figure 7) The high internal energy propionyl radicals correspond to $\mathrm{Cl}$ atoms produced from $\mathrm{C}-\mathrm{Cl}$ bond fission with low recoil kinetic energy (Figure 2).

of the spin-orbit state of the chlorine atoms. $E_{\mathrm{Cl}}$ is $0 \mathrm{kcal} / \mathrm{mol}$ if $\mathrm{Cl}$ is produced in the ${ }^{2} \mathrm{P}_{3 / 2}$ state and $2.5 \mathrm{kcal} / \mathrm{mol}$ in the ${ }^{2} \mathrm{P}_{1 / 2}$ state. ${ }^{21}$ Our experiments cannot distinguish between the two spin-orbit states. $E_{\text {int }}$ is easily determined once we have measured $E_{\mathrm{T}}$. The $P\left(E_{\mathrm{T}}\right)$ for the $\mathrm{CH}_{3} \mathrm{CH}_{2} \mathrm{CO}+\mathrm{Cl}$ recoil kinetic energy (Figure 2) shows that secondary dissociation occurs for some of the radicals from $\mathrm{C}-\mathrm{Cl}$ bond fission events that partition less than $20 \mathrm{kcal} / \mathrm{mol}$ to product translation. However, it is not until about $13 \mathrm{kcal} / \mathrm{mol}$ in $\mathrm{C}-\mathrm{Cl}$ recoil kinetic energy that all of the nascent propionyl radicals undergo dissociation. We attempted to fit the data with a sharp cutoff between the high and low recoil kinetic energy propionyl radicals, but did not obtain a satisfactory fit. Although one might try to explain the stability of the propionyl radicals from the lower $E_{\mathrm{T}}$ event by a centrifugal barrier to $\mathrm{C}-\mathrm{Cl}$ bond fission, our calculations show that this radical is not expected to partition much energy into rotation. Using structural parameters of propionyl chloride determined at the MP2/6-311G** level of theory by Durig et al., ${ }^{22}$ we calculated the rotational energy to be $0.5 \mathrm{kcal} / \mathrm{mol}$ at an $E_{\mathrm{T}}$ of $13 \mathrm{kcal} / \mathrm{mol}$. Thus, our observation that there is a range of $E_{\mathrm{T}}(\mathrm{C}-\mathrm{Cl})$ over which propionyl radicals can be produced as either stable or unstable likely results from the fact that the parent internal energy is a distribution with an average of 4 $\mathrm{kcal} / \mathrm{mol}$ but a significant spread. The radicals from $\mathrm{C}-\mathrm{Cl}$ bond fission events that partitioned $19 \mathrm{kcal} / \mathrm{mol}$ to $E_{\mathrm{T}}(\mathrm{C}-\mathrm{Cl})$ but are observed as stable in our work likely came from parent molecules with less than $4 \mathrm{kcal} / \mathrm{mol}$ vibrational energy. Figure 9 shows the internal energy distribution of the propionyl radicals and compares the value of $E_{\text {int }}$ to the enthalpy of reaction 2 . It is important to note that this figure shows $E_{\text {int }}$ under the assumption that the propionyl radicals are formed in coincidence with $\mathrm{Cl}\left({ }^{2} \mathrm{P}_{3 / 2}\right)$ and also that the parent molecules have $4 \mathrm{kcal} /$ mol in vibrational energy, neglecting any possible spread in vibrational energies.
The spread in $E_{\text {parent }}$ makes it difficult to identify the value of $E_{\text {int }}$ that marks the barrier to dissociation. Figure 2 shows that the highest $E_{\mathrm{T}}$ for propionyl radicals that can possibly dissociate corresponds to $20 \mathrm{kcal} / \mathrm{mol}$ of $\mathrm{C}-\mathrm{Cl}$ recoil kinetic energy. These radicals must also come from vibrationally hot propionyl chloride parent molecules. By eq 9 and $\left\langle E_{\text {parent }}\right\rangle=4$ $\mathrm{kcal} / \mathrm{mol}$, the propionyl radicals are assigned $E_{\text {int }}=15.8 \mathrm{kcal} /$ mol, but these propionyl radicals likely come from parent molecules with more vibrational energy than the average, so the $E_{\text {int }}$ is a bit higher than $16 \mathrm{kcal} / \mathrm{mol}$. This cutoff point in the $P\left(E_{\mathrm{T}}\right)$ can be seen in Figure 9. Figure 2 also shows that $E_{\mathrm{T}}=$ $13 \mathrm{kcal} / \mathrm{mol}$ marks the point where none of the nascent propionyl radicals are stable. These radicals should come from parent molecules with very little or no vibrational energy and have a $\mathrm{Cl}\left({ }^{2} \mathrm{P}_{1 / 2}\right)$ cofragment in the primary photodissociation step. Experiments in our group ${ }^{23}$ have shown that $\mathrm{C}-\mathrm{Cl}$ fission that proceeds by electronic predissociation yields $\mathrm{Cl}$ in both spinorbit states, so it is not unreasonable to expect $\mathrm{Cl}\left({ }^{2} \mathrm{P}_{1 / 2}\right)$ produced from propionyl chloride. In this case, taking $E_{\text {parent }}$ as $0 \mathrm{kcal} / \mathrm{mol}$ and applying eq 9 with $E_{\mathrm{Cl}}=2.5 \mathrm{kcal} / \mathrm{mol}$ gives an $E_{\text {int }}$ of $16.3 \mathrm{kcal} / \mathrm{mol}$. Therefore, we assign the barrier to dissociation of propionyl radical within the range of $16.3 \pm$ $1.5 \mathrm{kcal} / \mathrm{mol}$.

$\mathrm{HCl}$ elimination could occur by $\alpha$ - or $\beta$-elimination, so the identity of HCl's momentum-matched partner fragment is $\mathrm{CH}_{3}$ $\mathrm{CHCO}$ or $\mathrm{CH}_{2} \mathrm{CH}_{2} \mathrm{CO}$. These two $\mathrm{C}_{3} \mathrm{H}_{4} \mathrm{O}$ fragments are indistinguishable by the technique used in this study. Winter et al. used selectively deuterated propionyl chloride in a $10 \mathrm{~K} \mathrm{Ar}$ matrix to show that UV photodissociation exclusively yields $\mathrm{HCl}$ by $\alpha$-elimination. ${ }^{12}$ They explained this observation as likely due to a matrix effect. We plan to conduct our own experiments on deuterium-labeled propionyl chloride, $\mathrm{CD}_{3} \mathrm{CH}_{2}-$ $\mathrm{COCl}$, and probe for the $m / e=36\left(\mathrm{HCl}^{+}\right)$or $m / e=37\left(\mathrm{DCl}^{+}\right)$ signal to determine if the elimination occurs by a four- or fivecentered mechanism, or both. The data also show that in the internal energy range of the propionyl radical produced in this study, $10-35 \mathrm{kcal} / \mathrm{mol}, \mathrm{C}-\mathrm{H}$ bond fission to produce $\mathrm{CH}_{3}$ $\mathrm{CHCO}+\mathrm{H}$ does not compete to a significant extent with the $\mathrm{C}-\mathrm{C}$ bond fission channel that produces $\mathrm{CH}_{3} \mathrm{CH}_{2}+\mathrm{CO}$. This is in agreement with the higher energy requirement for the $\mathrm{C}-\mathrm{H}$ fission channel, $\Delta H_{0 \mathrm{~K}}=36.5 \mathrm{kcal} / \mathrm{mol}$, ${ }^{12}$ which is the lower limit for the reaction energy barrier and inaccessible for the range of propionyl radical internal energy.

Acknowledgment. This work was supported by the Chemical, Geosciences and Biosciences Division, Office of Basic Energy Sciences, Office of Science, U.S. Department of Energy, under Grant No. DE-FG02-92ER14305. The Advanced Light Source is supported by the Director, Office of Science, Office of Basic Energy Sciences, Materials Sciences Division, of the U.S. Department of Energy under Contract No. DEAC03-76SF00098 at Lawrence Berkeley National Laboratory. The Chemical Dynamics Beamline is supported by the Director, Office of Science, Office of Basic Energy Sciences, Chemical Sciences Division, of the U.S. Department of Energy under the same contract. L.R.M. was partially supported by a U.S. Department of Education GAANN Fellowship. M.J.K. was supported by a NSF Graduate Research Fellowship. The authors thank David E. Szpunar for guidance during data analysis. L.J.B. acknowledges Rich Bersohn's warm collegiality and strong physical and chemical insight. He touched us all, and he lives on in the hearts of his family and his twin brother Malcolm. 


\section{References and Notes}

(1) Li, H.; Li, Q.; Mao, W.; Zhu, Q.; Kong, F. J. Chem. Phys. 1997, 106,5943

(2) Hall, G. E.; Metzler, H. W.; Muckerman, J. T.; Presses, J. M.; Weston, R. E., Jr. J. Chem. Phys. 1995, 102, 6660.

(3) Kim, S. K.; Guo, J.; Baskin, J. S.; Zewail, A. H. J. Phys. Chem. 1996, 100, 9202.

(4) Seinfeld, J. H.; Pandis, S. N. Atmospheric Chemistry and Physics: From Air Pollution to Climate Change; John Wiley \& Sons: New York, 1998.

(5) Mereau, R.; Rayez, M.-T.; Rayez, J.-C.; Caralp, F.; Lesclaux, R. Phys. Chem. Chem. Phys. 2001, 3, 4712.

(6) Martinez-Nunez, E.; Vazquez-Rodriguez, S. A. J. Mol. Struct. 2000 $556,123$.

(7) Martinez-Nunez, E.; Pena-Gallego, A.; Vazquez, S. A. J. Chem. Phys. 2001, 114, 3546

(8) Watkins, K. W.; Thompson, W. W. Int. J. Chem. Kinet. 1973, 5 , 791

(9) Kerr, J. A.; Lloyd, A. C. Chem. Commun. 1967, 164.

(10) Kerr, J. A.; Lloyd, A. C. Trans. Faraday Soc. 1967, 63, 2480.

(11) Chatgilialoglu, C.; Crich, D.; Komatsu, M.; Ryu, I. Chem. Rev. 1999, 99, 1991.
(12) Winter, P. R.; Rowland, B.; Hess, W. P.; Radziszewski, J. F.; Nimlos, M. R.; Ellison, G. B. J. Phys. Chem. A 1998, 102, 3238.

(13) Schalley, C. A.; Blanksby, S.; Harvey, J. N.; Schroder, D.; Zummack, W.; Bowie, J. H.; Schwarz, H. Eur. J. Org. Chem. 1998, 987.

(14) Person, M. D.; Kash, P. W.; Butler, L. J. J. Chem. Phys. 1992, 97 , 355.

(15) North, S. W.; Blank, D. A.; Gezelter, J. D.; Longfellow, C. A.; Lee, Y. T. J. Chem. Phys. 1995, 102, 4447.

(16) Yang, X. M.; Lin, J.; Lee, Y. T.; Blank, D. A.; Suits, A. G.; Wodtke, A. M. Rev. Sci. Instrum. 1997, 68, 3317.

(17) Peterka, D.; Ahmed, M. Personal Communication.

(18) Samson, J. A. R.; Shefer, Y.; Angel, G. C. Phys. Rev. Lett. 1986, $56,2020$.

(19) Gallagher, J. W.; Brion, C. E.; Samson, J. A. R.; Langhoff, P. W. J. Phys. Chem. Ref. Data 1988, 17, 9.

(20) Mueller, J. A.; Butler, L. J. Unpublished results.

(21) Davies, P. B.; Russell, D. K. Chem. Phys. Lett. 1979, 67, 440.

(22) Durig, J. R.; Li, Y.; Shen, S.; Durig, D. T. J. Mol. Struct. 1998, $449,131$.

(23) Liu, Y.; Butler, L. J. J. Phys. Chem. A, to be submitted for publication. 